\title{
Application of digital technologies to increase business activity in construction
}

\author{
Natalia Safronova ${ }^{1, *}$, Alexey Budakov ${ }^{1}$ and Elena Ivankina ${ }^{1}$ \\ ${ }^{1}$ Russian Academy of national economy and public administration, Prospect Vernadskogo, 82, 119571 \\ Moscow, Russia
}

\begin{abstract}
Digitization collects all construction sites. There is no alternative to the use of digital tools on construction sites. However, the implementation of the strategy of digitization is especially necessary for a construction company. As in all sectors, the main digitization industry is now similar to a large construction site. All construction companies should find their way on a wide field of digitization.
\end{abstract}

\section{Introduction}

Many believe that behind the letters BIM lies the name of the software.

But such a simple definition cannot be given. BIM technologies in designing based on the creation of a three-dimensional building model, but in this case the model is not just a set of geometric elements and textures.

In fact, this model consists of virtual elements that are in reality and have certain physical properties.

BIM technology allows you to design a building and even before the start of construction to fully calculate and determine all the processes that occur in it.

Today, this technology has received a boost in development, and if earlier to work with it had to install special complex and professional programs, today there are "cut" and simple programs for smartphones and tablets. This allows customers and developers to quickly and easily access the BIM model. This brings technology to a new level.

The first and most obvious advantage of $3 \mathrm{D}$ visualization is a visualization that is the most common way of using BIM technology. This allows not only to present the project beautifully to the customer, but also to find the best design solutions instead of the old ones.

The second advantage is centralized data storage in the model, which allows you to efficiently and easily manage changes. When you make a specific change to a project, it is immediately displayed in all views: floor plans, facades, or sections. It also significantly improves the speed of project documentation creation and reduces the possibility of errors.

The study revealed that the use of BIM technology contributes to the economic efficiency of investment and construction projects. In addition to the noted economic effects, the study revealed a number of non-economic effects that contribute to the overall competitiveness of Russian enterprises in the investment and construction sector.

\footnotetext{
*Corresponding author: safronova@ranepa.ru
} 


\section{Materials and methods}

Minimal losses from all the variants of investment distribution characterize the most effective way of allocating funds for construction.

That is why, within the framework of this article, the main methods of scientific and practical research were used.

The study was conducted by the method of questioning (questioning) the opinions of representatives the construction industry, in the STI BIM technology. Also the analysis of international expertise was carried out, the assessment was carried out effectively.

The research article also examines the practical and scientific experience, the article deals with Nezhnikova, E. «Criteria for classification of competitive housing projects in terms of their environmental friendliness» $[1]$.

\section{Discussion}

Currently, the development of BIM technologies is also given great attention by the scientific unit, as 10-15 years ago. A distinctive feature of this field of business is the fact that throughout the development of the scope of the said technology, it has not lost relevance, attracted a large number of industries: both civil and military, and in special construction.

In particular, when implementing energy service contracts, BIM information technologies are also used, which allows to increase the effectiveness of their implementation. Some of these issues are covered in the scientific article «Influence of supply and demand factors at the development of environmentally responsible housing and utilities sector in the Russian Federation» [2].

The possibility of such transition is caused by the intensive development of information technologies and the advent of specialized software products, which are not directed to the creation of a digital information model of the object building, includes everything-

in-depth information about you. The presence of such a model of the building object is not only to use the automated means for the realization of various types of analysis and tests, the output of the project and work documentation, visual planning and the optimization of the process of building, the evaluation of the estimated value, of the reception of other data, but also controlled access to the data about the object to all interested persons in

The methodology of information modelling in BIM construction is an innovative alternative to the traditional approach to the design, construction and operation of buildings and structures. BIM is most fully implemented as part of the integrated implementation of projects in the construction of the IPAD. In the same way BIM / IPD technologies should be incorporated into training [3]

Currently, the construction industry in some cases uses laser scanning

As always, the choice of devices and shooting techniques depends on the specific goals and objectives that are designed to solve laser scanning. However, summing up the experience, it is possible for industrial enterprises to distinguish four main types of laser scanning:

1. Scan frame (overview). It is performed by long-range and medium-range scanners. Typically, this scan is not high density and granularity. The average density of point clouds is 5 to $7 \mathrm{~cm}$ this scan covers mainly large objects and gives an idea about their sizes, styles, designs and engineering constructions located on the industrial site. Typically, in such a cloud there are shadow zones (zones behind objects, where there are no measurements). In such places may well hide some useful items. 
An array of measurements (point cloud) is guaranteed to contain objects of the order of $1 \mathrm{~m}$. this type of scanning is performed as a basis for a more detailed scan, and can also be used as a separate type of work, where there is no need for high detail display of objects: the basis for drawing up or updating the master Plan, creating an overview of the 3D GIS model, visualization, etc.

2. Local scan. It is performed on a small area of an industrial object when there is no need to scan the entire object. For example, when it is necessary to disassemble and replace only one pipeline.

In this case the phase scanners scanning only the details of the investigated pipeline, its supports, hangers and the surrounding area of a few meters.

3. Full scan. Detailed and continuous shooting is performed using the fast phase-based scanners middle of the battle. Represents the most complete and detailed scanning of all object. Measurements from the scanner cover about $95 \%$ of the object surface. The scanner is installed in all areas and levels of the object, as well as in any place where it is necessary for shooting and technologically possible.

Full scan allows all sides to cover all parts and elements of an object with dimensions. Can virtually eliminate the presence of shadow zones. The point cloud will contain everything, even the smallest objects. This type of scanning is successfully used in the process of construction control and as an Executive 3D survey in the interests of the project reconstruction of the object.

4. Medium granularity scanning. This type of scan is ordered for the sake of imaginary savings. Term for reference set a limit on the subject of interest. For example, in a set: "pipes with a diameter of metal will be scanned-only carriers; the remaining elements only if at least one of their sizes exceeds $200 \mathrm{~mm}$."

Unfortunately, the laser scanner is not yet able to choose what to scan for any criteria. Only the operator can pay special attention to the required objects, ignoring the smaller ones. But in practice, it is easier and faster to scan the whole thing than to deal with the details. After all, both large and small elements are arranged evenly throughout the object.

Figure 1 depicts the entire process, within which BIM technologies are used.

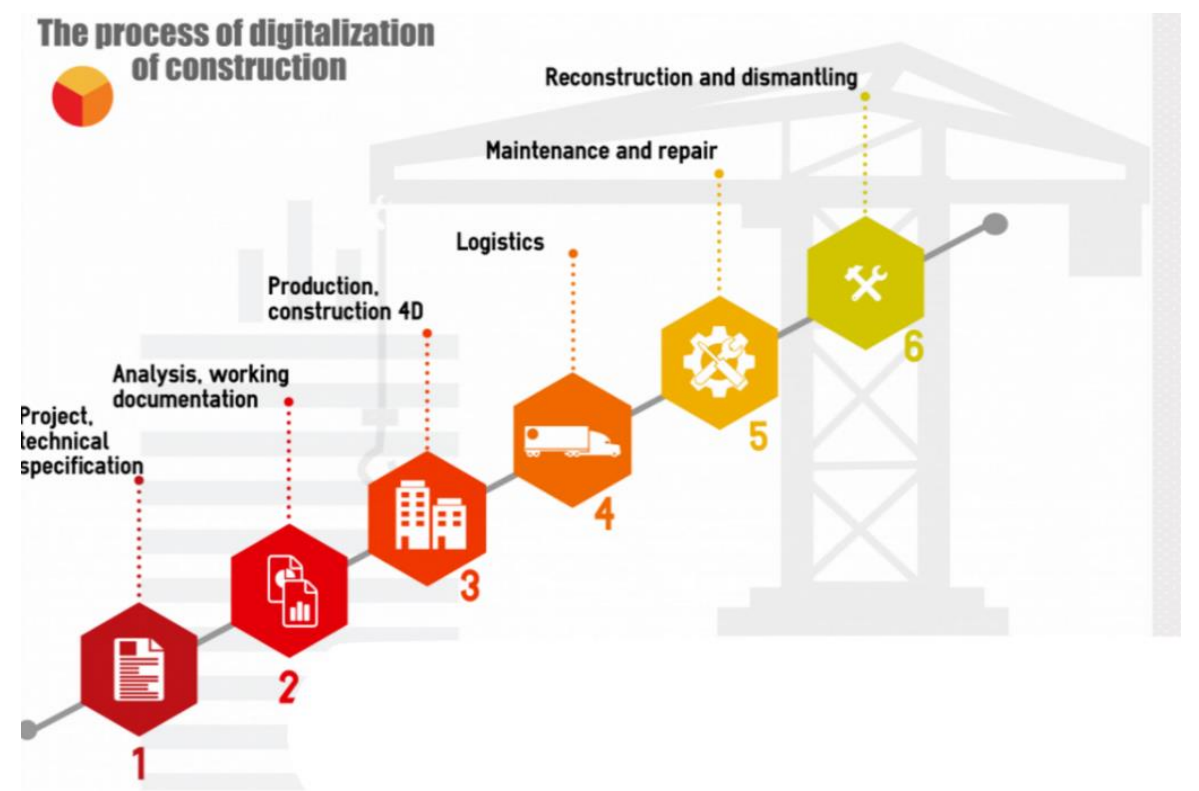

Fig. 1. The process of digitalization of construction. 
Another advantage is data management. After all, not all the information that is in the BIM model can be presented graphically. Therefore, the model also contains catalogs, specifications that determine the cost of creating a project. In the model there are also financial performance. Thus, the estimated cost of the project is determined immediately after changes are made. Well, about saving money it is impossible to forget.

The introduction of BIM design technologies will allow to reduce financial costs and to significantly reduce the time of commissioning. For this reason, most construction companies try to use modern methods of information modeling in their practice.

A description of the life cycle in several stages of the BIM simulation is shown in Figure 2.

In particular, some issues of improving resource efficiency at all stages of design and construction with the help of software technology "BIM" objectively considered in scientific papers Nezhnikova E. [4].

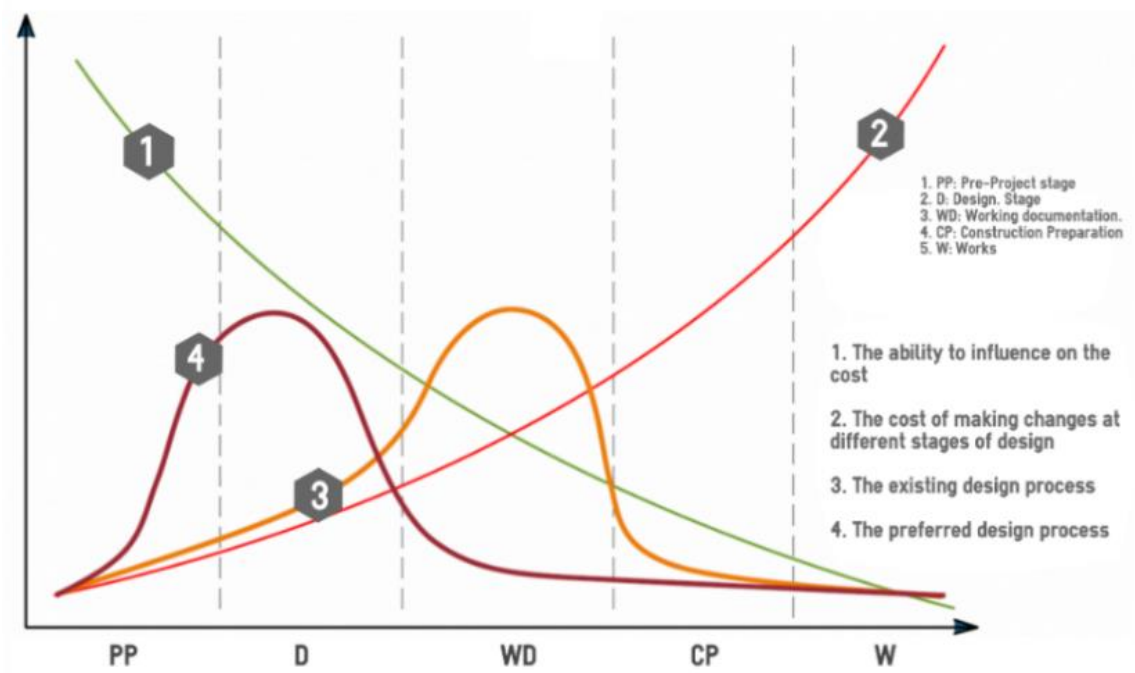

Fig. 2. Data developers' developers, General contractors.

With the conscious application of 'integral' approach of the entire process chain costs construction can be reduced by $15 \%$. Along with lower costs, there is an obligation to increase resilience. This is evident in the value chain.

Consistent consideration of the entire life cycle of buildings on this principle pays special attention to the management of information about the objects. Depending on the model contract, the situation with construction projects can be black if during construction you still have to make changes or correct errors. As a rule, is it not easy to understand the project plans to the last detail and see during construction is always priorities. It is often difficult to imagine the specific appearance of a building based on visualizations. Often they do not correspond to what will be built in the end. The main task for all participants in the building is a problem-solving context.

We must put the relationship between Customers and contractors and designers in a new way. Based on the digitization strategy, special departments must be created to act as a rotating disk when processing data. Official programmes are currently being implemented in the following countries, as shown in the figure. 
Figure 3 shows a diagram of the relationship between the application of BIM technology and its impact.
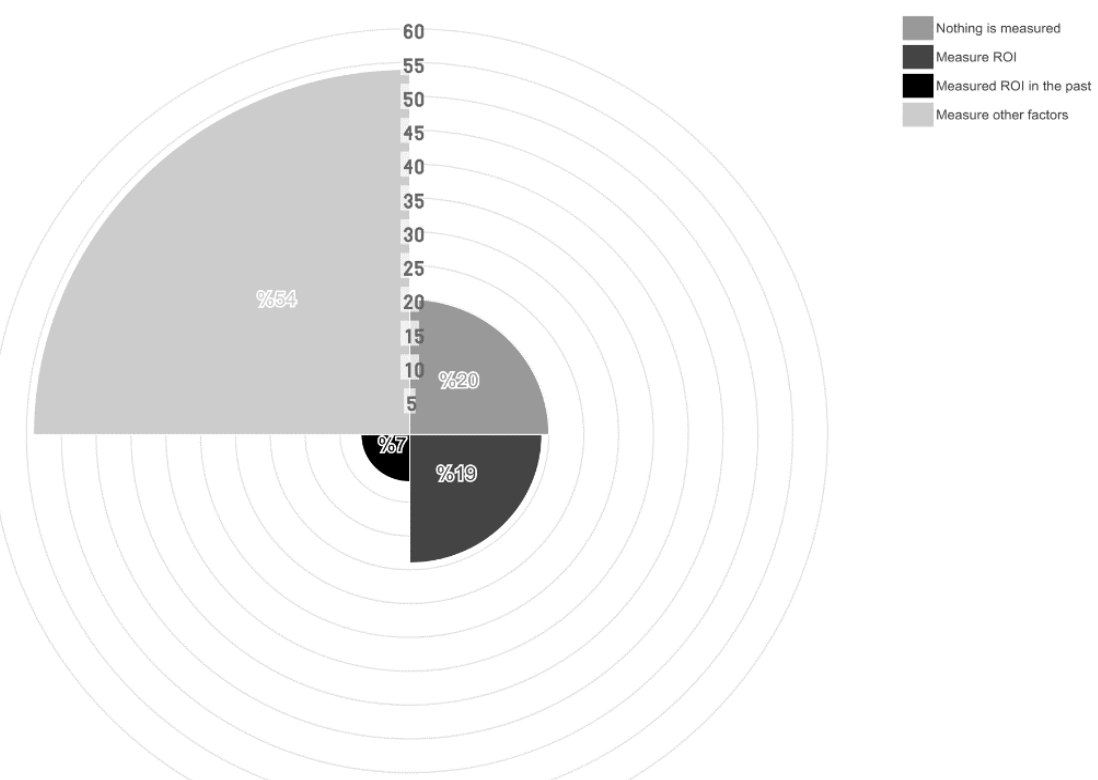

Fig. 3. The method of open interviews with representatives of the organizations of investment and constructiontional sphere.

It's been a decade since the BIM term appeared. During this time, most of the world's leading design companies have adapted this technology and successfully used it to carry out many projects. Nevertheless, most of us look at BIM rather short-sightedly, besides, these views differ from country to country due to different traditions and legislations.

We bring to your attention a brief overview of the approaches to BIM, implemented in different countries. Figure 4 shows countries in which BIM technologies are normatively fixed at the official level.

\section{OFFICIAL PROGRAMME FOR THE INTRODUCTION OF BIM}

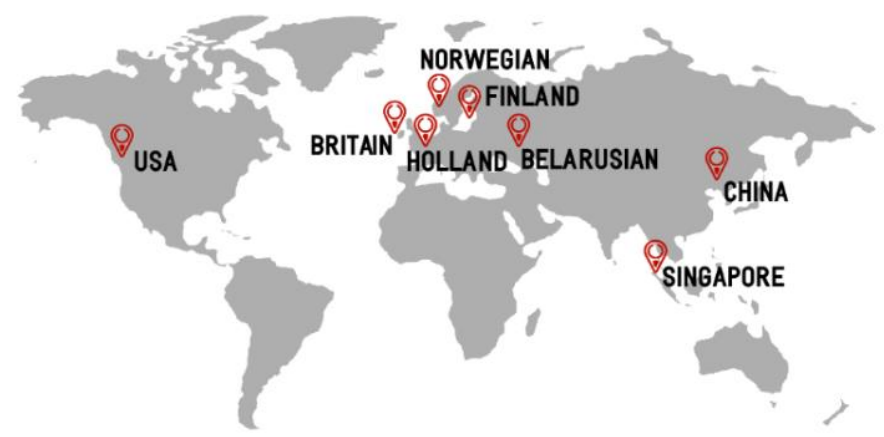

Fig. 4. Official program for the introduction of BIM. 
The non-preparation of the customer of the construction project is completely, to understand, to accept and to evaluate the advantages of the technologies of information modelling (BIM) in the last time is almost as the main obstacle to the introduction of your introduction.

Figure 5 shows a graph with information on the structure of mandatory use of BIM technologies

in the implementation and execution of public construction contracts in different European countries.

\section{Requirements for the use of BIM by commercial entities}
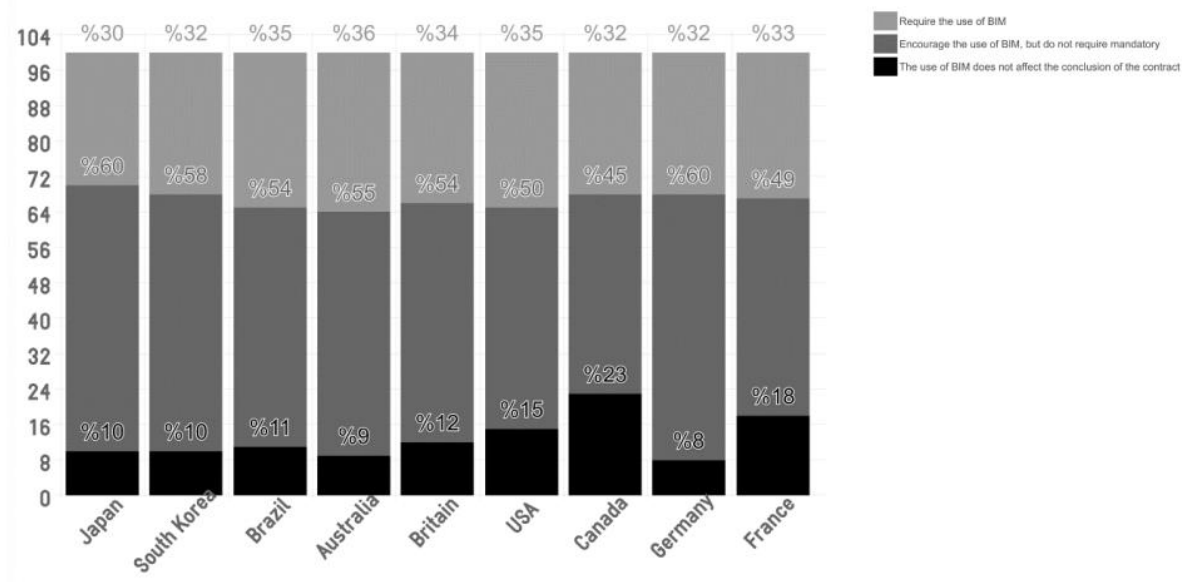

Fig. 5. The data of real estate companies.

Data modeling is gaining popularity in the implementation of investment projects. Analysts predict that in the coming years almost the entire amount of information inside the system engineer-Manager-supplier-contractor-digital. Analysis of modern Russian practice shows a certain delay in the construction industry, while there is information that almost $100 \%$ of Russian projects are completed in violation of the schedule and exceeded the budget.

This includes safety in the construction of facilities, safe operation of constructed facilities, Information security of data in the process of development and operation of facilities, and economic security of participants in investment and construction projects and operating organizations.

Figure 6 shows a graph with information on the growth (decline) of the index of entrepreneurial confidence in the context of the number of participants in the construction market on the portfolio of construction orders [5]. 


\section{The dynamics of business confidence in construction}

balances, \%

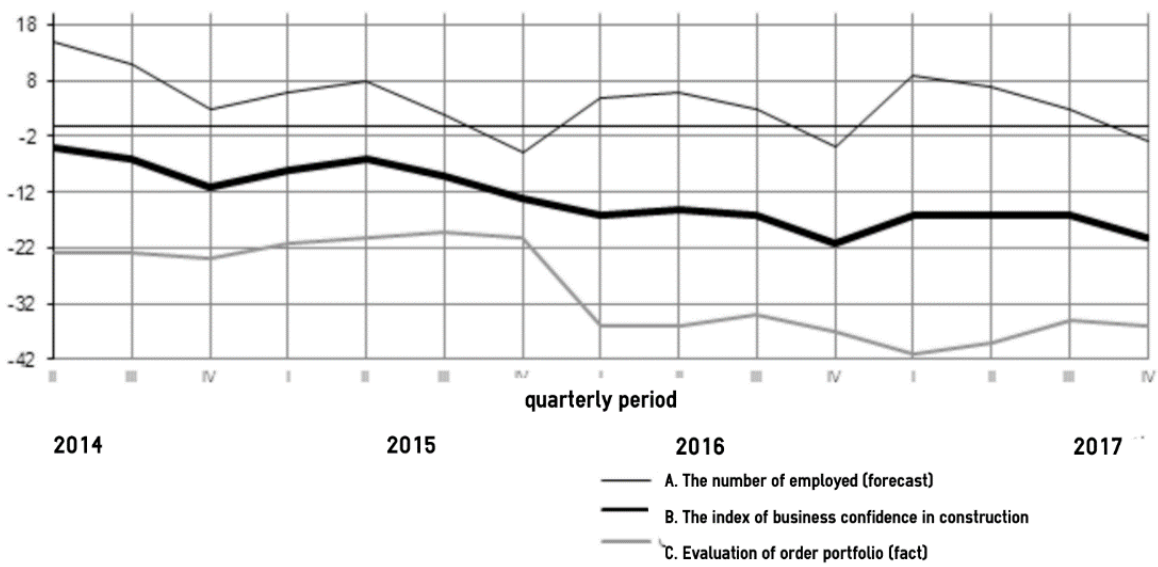

Fig. 6. State statistics service of the Russian Federation.

During certain periods of economic development of the Russian Federation the index of entrepreneurial confidence grew for more than 10 years. This is also due to the use of information technologies in construction.

Figure 7 shows a graph showing the dynamics of growth (decline) of the index of entrepreneurial confidence for the period from 1998 to 2016 [6].

\section{The index of business confidence in construction in Russian Federation}

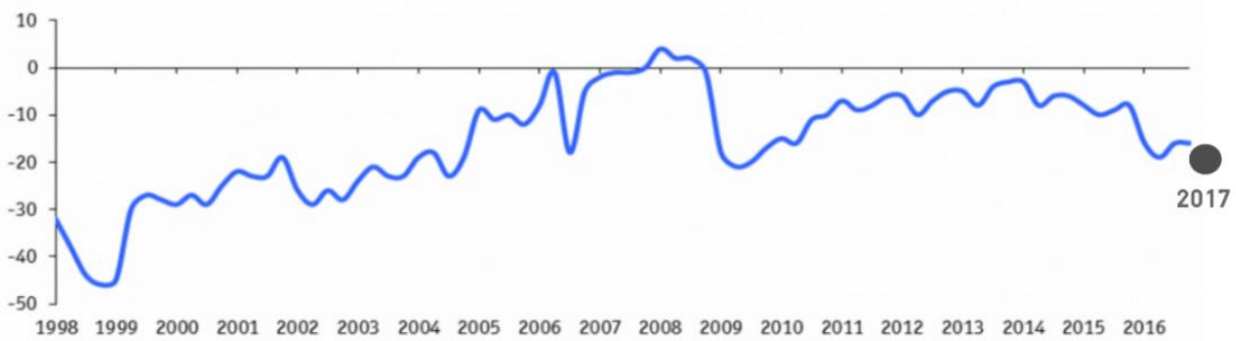

Fig. 7. State statistics service of the Russian Federation.

The Russian Federation monitors the development of BIM technologies, including at the legislative level

This is the plan for the introduction of BIM-technologies in the field of industrial and civil construction, Verde min. Russian order No. 926 / PR of December 29, 2014 was developed in cooperation with Ross, an Expert at the Government of the Russian Federation and other institutions for economic modernization and innovative development.

Now practice when in the course of architectural and construction design the computer model of the new building bearing in itself all data on the future object is created is more often applied. Design automation systems using BIM technology allows you to go into 3D Format all the elements and systems of the building, calculate the different options of their 
company, and their priority in accordance with existing norms and standards, analysis of the performance of future buildings, simplifying the choice of the optimal solution.

This, in turn, will be the instrument of cost optimization and diversification of the shortage of construction resources and labour. In figure 8 you can see factors limiting the production activity of construction.

\section{Factors limiting the production ctivity of construction companies}

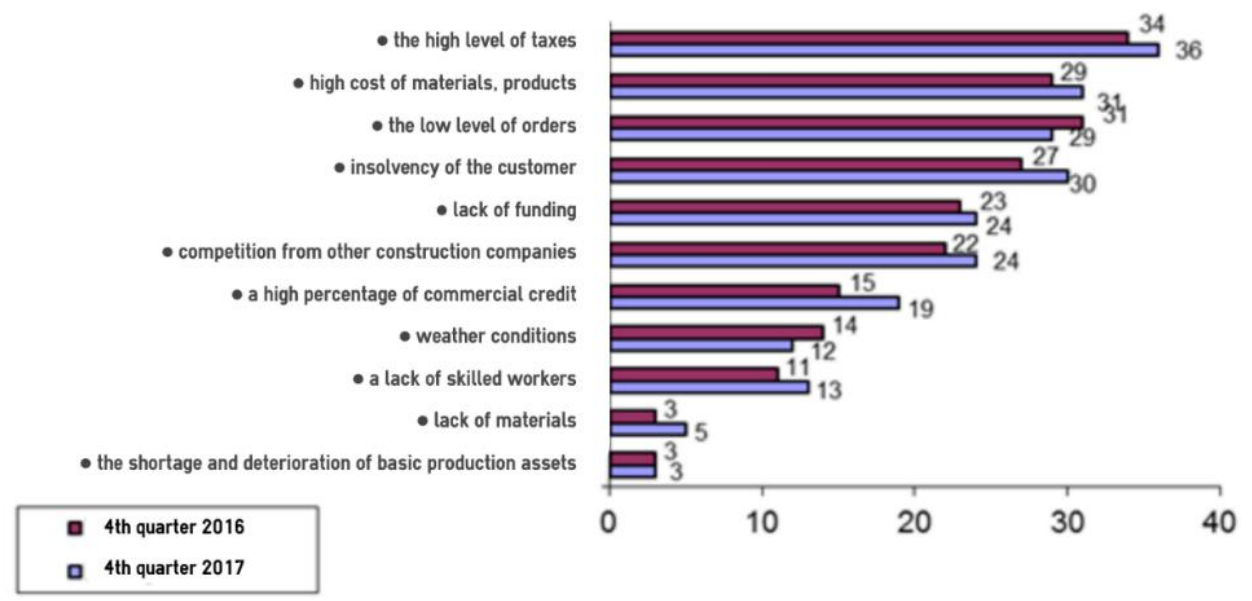

Fig. 8. State statistics service of the Russian Federation.

According to the plan, the edges of the poet's technology implementation information model, by March 2015 the Expert Council under the government of the Russian Federation should select the severity of pilot projects, and by November 2015 it is planned to conduct their expertise in order to establish requirements for the use of BIM technology. Ministry of construction and housing and communal services of the Russian Federation confirmed the results of the analysis at the end of 2015 will prepare and submit for approval to the government of the Russian Federation a list of regulatory and technical acts, educational standards that will be developed and Jenny.

It is expected that the work on making these changes to the Ministry of economic development of Russia together with No" E "in Glavgosexpertiza of Russia and the national Association of prospectors and the project (prize) of gravity will be completed by the end of 2016.

A year later, drew 2017, it is planned to train specialists in the use of the information technology model in the field of industrial and civil construction, as well as experts of the examination bodies.

The Department coordinates the application, as well as performs work on calculations and cost estimates. This approach requires rethinking the entire data flow.

First, bring the right data in the right amount to the executors at the construction site, create a new data processing to prepare for the job.

Introduction in the town-Planning code of the Russian Federation of the changes providing concerning the capital construction projects which are in property of physical 
persons is provided by part 2 of article 48.2 of the town-Planning code of the Russian Federation

The government Of the Russian Federation about establishment of the list of the works and services necessary for operation of the specified capital construction projects, the order of their accomplishment and delivery;

- powers of the Government of the Russian Federation on establishment of the order of carrying out monitoring of the prices of performance of works and rendering the services necessary for operation of the specified capital construction projects;

- powers of the authorized Federal Executive authority on the statement of the technique of determination of estimated prices for performance of works and rendering the services necessary for operation of the specified capital construction projects;

- powers of the authorized Federal Executive authority on the statement of the classifier of capital construction projects according to their functional purpose;

- powers of the authorized Federal Executive authority on approval of the method of categorization of building materials, products and structures and determination of target dates of their operation (by categories);

- powers of the authorized Federal Executive authority on approval of the technique of preparation of the feasibility study of investments in construction taking into account budget standards on construction and demolition of capital construction projects, and also marginal costs on their operation;

- creation of the Federal state information system of pricing in construction, operation and demolition of the specified capital construction projects (with reference to expansion of functional purpose of Federal state information system of pricing in construction);

- setting the requirements in accordance with which the operation of the specified objects of capital construction is carried out in the framework of execution of works and rendering of services in approved Government of the Russian Federation the list of prices above marginal costs to perform such work and services;

- powers of the authorized Federal Executive authority on the statement of the technique of determination of limit expenses on performance of works and rendering the services necessary for operation of the specified capital construction projects.

It also provides for amendments to the Town planning code of the Russian Federation, providing for: optimization of requirements for the composition and content of project documentation of capital construction projects in order to reduce the development time.

Clarifying the content of information entered in informtica, provides for amendments to the town planning code of the Russian Federation providing for:

- optimization of requirements for the composition and content of project documentation of capital construction projects in order to reduce the development time;

- specification of the content of the information which is subject to entering into information system of ensuring town - planning activity, including inclusion in structure of the plan of land and underground communications in which data on the arrangement of the existing and offered networks of engineering providing, electric networks are provided;

- the vesting of the system operator's functions of the Executive Committee authorized the Executive bodies of the constituent entities of the Russian Federation or subordinated public organizations;

- Improving the institution of zones with special conditions of use of territories in the definition of the General order of creation of these zones and their regenerative legal system for urban planning, including the inclusion of a plan surface and underground communications, which provides information about the location of existing and proposed network engineering, power networks and structures; 
- assignment to the operator of functions of authorized Executive authorities of subjects of the Russian Federation or subordinated state organizations;

- improving the Institution of zones with special conditions for the use of territories in determining the General procedure for the creation of these zones and their legal regime.

\section{Summary}

The BIM technology that allows to create a multidimensional model of the construction object, which will contain all the information about it. At the same time, this model is used not only for construction, but also for the operation of the facility. Therefore, it is wrong to think that BIM / Tim-it's just a 3D graphics projection.

The range of possibilities of the technology is very wide. Information modeling involves a completely new approach to the creation and management of the building, which will take into account everything.

All this allows to avoid possible alterations in the construction, to reduce the cost of construction, and most importantly to save time. The introduction of BIM technologies has made it possible to make the right decisions at the life cycle stage- from investment to operation and even demolition. However, this technology also requires financial costs. In particular, it is necessary to purchase special software and simulators. But these costs are further offset by a decrease in the cost of designing and organizing the construction of the building.

\section{The effectiveness of the implementation

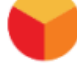

The increase in the net present value (NPV)

The growth of the profitability index (PI)

Increase in the internal rate of return (IRR)

Reduction of the payback period of the investment and construction project

Reducing the cost of a project that is linked with reduced costs at the construction stage
$25 \%$

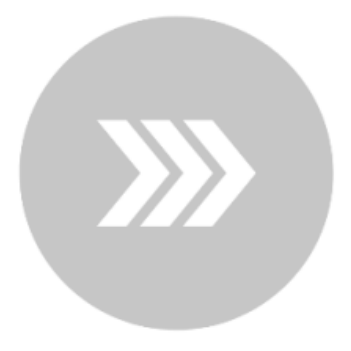

$14-15 \%$

$20 \%$

$17 \%$

$30 \%$

Fig. 9. Analysis of the Russian investment and construction forum-2016.

On the other hand, with the creation of a document management system, information flows in the organization should be reworked. The goal is to become a reality of paperless office. Currently, data on accounting of debtors and creditors are processed by the system, as well as the entire process of obtaining personnel and procurement in the it sector. The electronic management system (EMS) should also be created in the form of an electronic newspaper at home according to the organizational structure. Correspondence, including construction materials, should be kept in electronic form only. For example, manipulation of documents becomes almost impossible. Only plans, production contracts and the sureties 
will still be kept in paper form. Also weekly plans on paper for dumps and builders will soon remain in the past.

At the same time, only as much data as needed and as little as possible to get to the construction site, so that the data flow does not occur and guides builders and polygons or machinists are overloaded. Executors also guarantee and reverse flow of information from the site to the cloud, where the data is processed from the technical office and again for future use.

Digitization takes place with different steps, and different levels differ. The tier 1 technical office creates a 3D model based on PDF documents and 2D plans and provides data for surveying instruments and machine control. At level 2, engineers and architects work on the same model and transmit the data to the Executive Department. Several project teams are using the same model, which allows at any time to get an idea about the status of implementation. Since the change of strategy, the company has implemented major projects on a new approach and at different levels.

Data quality control has become a critical success factor. "Our internal projects are of the highest data quality, and construction management is a kind of watch. This gives us better data quality," Stalder said. External data are already being requested at the subCommission stage in accordance with certain directives, which improves interaction with developers and partners. All data are processed by the technical Bureau and provided, for example, for machine control, for the use of unmanned aerial vehicles, for total stations and measuring instruments.

The latest generation camera attached to the crane bracket photographs the construction site from a certain place every day. Then the data-due to the accuracy of the camera, even the masses can be discarded-can be used for all projects. For example, you can check if the electrician has installed in the right place.

This methodology ensures higher quality of construction projects, as well as greater safety in planning costs and deadlines.

The project Manager should not be a programmer but needs to have the knowledge about data processing processes for optimal use", special engineering work is still in demand, but contractors in the future are increasingly involved in the constructive process of construction.

\section{Conclusion}

The conversion is even faster. Construction management can expand the scope of its activities on the construction site. Building information modeling requires reorganization of data flows throughout the enterprise. Builders are considering the possibility of increasing the life cycle of the building. Because operation and maintenance cause high costs, which should be taken it is taken into account when planning.

Evaluation of safety engineers use the European procedure, which projects into the BIM model. The expert regularly checks the construction site, photographs and enters the collected data into the computer.

The system calculates the security index in dynamics and in partitions. Data and reports collected by the engineer are transferred to the Manager. Timely introduction of necessary changes allows to increase safety of the personnel participating in construction works, and also is effective tools of increase of investment confidence in branch in connection with transparency of system.

As you can see, the BIM building model is ideal for use at all stages of the private, commercial and commercial real estate sector (planning, construction and use. 


\section{References}

1. E. Nezhnikova, IOP Conf. Series: Earth and Environmental Science 90, 012161(2017) doi:10.1088/1755-1315/90/1/012161

2. N.B. Safronova, A.R. Urubkov, A.S. Budakov, M.Myltsev, Serbian journal of management 11(2), 261-273 (2016) ISSN: 1452-4864 (print), 2217-7159 (online)

3. A.M. Spryskov, D.S. Privorotsky, E.V. Privorotsky, N.A. Yashina, Proceedings of the Samara scientific center of RAS, 4-1 (2016)

4. E. Nezhnikova, IOP Conf. Series: Earth and Environmental Science 90, 012162 (2017)

5. http://www.gks.ru/wps/wcm/connect/rosstat_main/rosstat/ru/statistics/enterprise/buildi $\mathrm{ng} /$

6. http://www.minstroyrf.ru/press/o-bim-tekhnologii-v-oblasti-stroitelstva/ 